\title{
Employing Co-op Employer Evaluations to Assess Outcomes
}

Parker, W J; *Fondacaro R; **Nespoli O.

Associate Dean, Cooperative Education and Professional Affairs, Faculty of Engineering, University of Waterloo, Ontario Canada

\section{INTRODUCTION}

The Faculty of Engineering at the University of Waterloo is preparing to employ outcomes-based assessments to inform program improvement as required by the Canadian Engineering Accreditation Board (CEAB) and the Ontario Council of Academic Vice Presidents (OCAV). Engineering at Waterloo requires all students to complete five 4-month work terms to graduate; a model of Co-operative education that involves a sequence of alternating work and academic terms. Upon completion of each work term employers complete a Student Performance Evaluation (SPE) that provides students with feedback on their work term and is employed to assign a grade to the student for the term. This presentation will describe an innovative use of historical SPE information to initiate a process that will lead to their use for outcomesassessment for program enhancement.

\section{APPROACH}

The dataset available for this study consisted of approximately 21,000 records that represented three years of co-op work term evaluations and spanned 12 engineering programs. Within each program, evaluations ranged from work terms 1 to 5 (of a total of 6 possible work terms) and hence represented a broad range in student seniority. The SPE's have two sections: 1 ) a rubric that requests feedback on nineteen questions related to the student's performance, attitudes, competencies and skills and each question has five possible responses ranging from Excellent to Unsatisfactory and includes a "Not Applicable" category; 2) written feedback on the student's "Areas of Strength" and "Areas for Development".

The questions in Section 1 of the SPE were categorized subjectively into six of the CEAB outcomes (Professionalism, Lifelong Learning, Project Management, Individual and Teamwork, Problem Analysis and Communication). For each question in each SPE of the dataset, responses in the top two categories (excellent and good) were considered as having satisfied the outcome. Data was then aggregated by engineering program for assessment of the performance of students with respect to the outcomes. Initially the performance of students in their last work term (i.e. nearest to graduation) was examined for each calendar year.

RESULTS

Figure 1 presents an example of the type of data that was collected on professionalism-related questions for students in their fifth work term in one program. In general, it was found that the responses to the various questions that addressed a specific outcome were consistent with each other. For example, there are five questions that address issues of Professionalism and for most years these five responses fell within a $10 \%$ range.

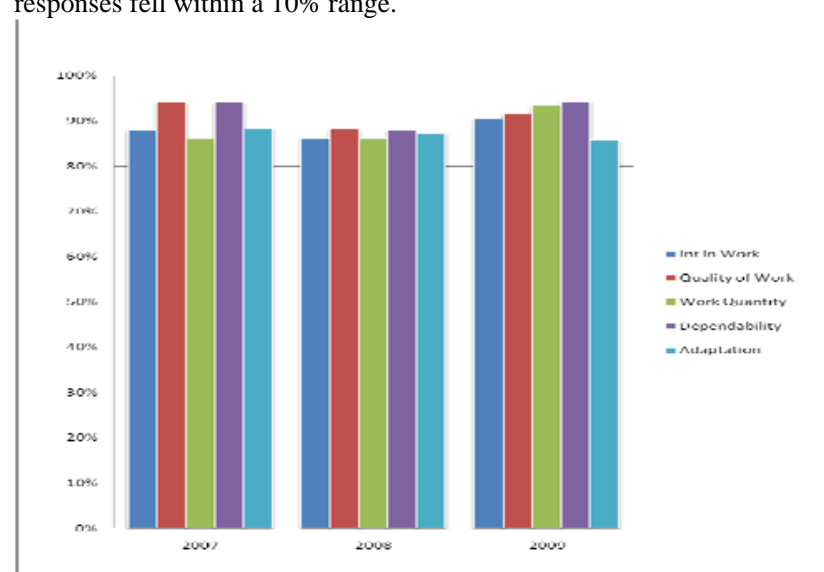

Figure 1 Example of responses related to professionalism questions for students in their fifth work term one program

In addition, responses to questions associated with each outcome were averaged to obtain one data point for each outcome for each SPE. This facilitated trend plots that demonstrated student performance versus seniority (i.e. work terms 1-5) -- an assessment of the development of competencies as students progressed through their program. Figure 2 presents an example of plots of this nature. With a few minor exceptions it was found that performance in each outcome improved as students became more senior. It was interesting to note that the development of competency in outcomes occurred at different rates and at different periods in the student careers.

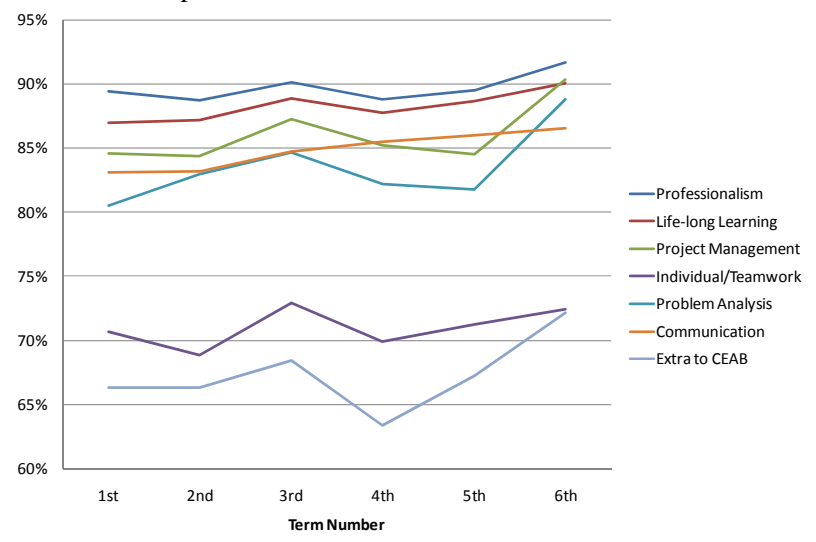

Figure 2 Example Plot of Outcomes versus Work term Number

Figure 3 presents an example of a word-prevalence analysis of the textual responses provided by employers. A preliminary evaluation of the textual responses indicated that students' 'ability to learn' was the most frequently reported area of strength for both work terms 1 and 5, and that 'communication' (oral, written, presentation etc.) was the most frequently reported area for recommended development for both work terms 1 and 5 .

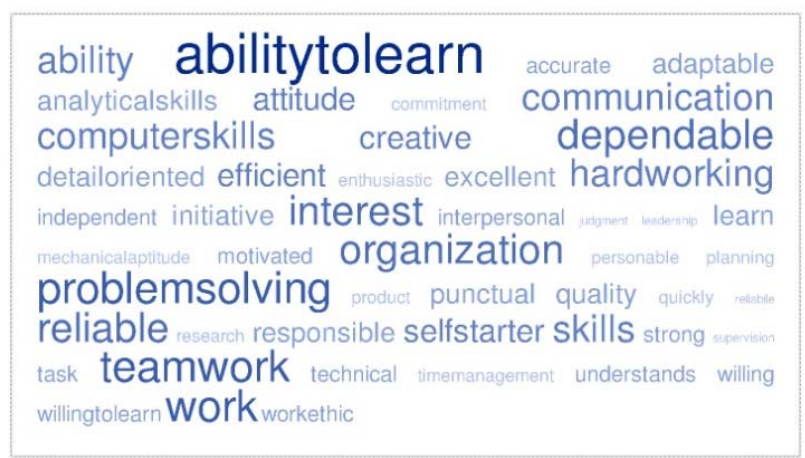

Figure 3 Example of Word-Prevalence Analysis of Textual Responses

\section{DISCUSSION}

In summary, the University of Waterloo has access to a substantial database of student assessment that has been provided by our co-op employers. The information provides clear indication of student strengths and areas for improvement. Moving forward, it is planned to revisit the questions employed in the SPEs with the objectives of further refining them to provide out-come specific data. The information that is being generated will be provided to the program curriculum committees to facilitate enhancement of the programs with respect to these important outcomes.

\section{AFFILIATED INSTITUTIONS FOR CO-AUTHORS}

* Director, Student and Faculty Relations, Cooperative Education and Career Services, University of Waterloo, Waterloo, Ontario

** Director of Curriculum Development

Department of Mechanical and Mechatronics Engineering University of Waterloo 